\title{
Treatment of severe localized pulmonary interstitial emphysema by selective
} bronchial intubation

\author{
J. E. OLIVER* \\ M.B., B.S., D.C.H.
}

I. J. SMITH†

M.B., Ch.B., M.R.C.P.

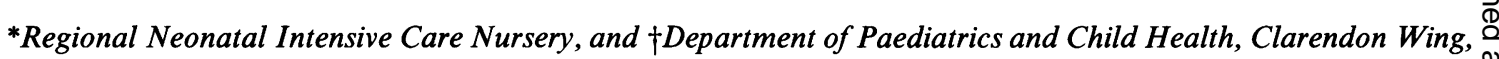
General Infirmary at Leeds, Great George Street, Leeds LSI 3EX

\begin{abstract}
Summary
A pre-term infant being ventilated for respiratory distress syndrome developed severe localized pulmonary interstitial emphysema which was successfully treated by selective bronchial intubation.
\end{abstract}

KEY WORDS: pulmonary interstitial emphysema, despiratory distress syndrome, pneumothorax, patent ductus arteriosus.

\section{Introduction}

Pulmonary interstitial emphysema (PIE) occurs in babies being ventilated for respiratory distress syndrome. It is often an incidental radiological finding, but may occasionally be so marked as to result in bulla formation with mediastinal shift.

The mortality is high (Coradello, Fodor and Simbruner, 1980) and several treatments have been suggested including rapid hand ventilation with $100 \%$ oxygen ( $\mathrm{Ng}$ and Easa, 1979), lobectomy (Bamer et al., 1980) and selective bronchial intubation (Brooks et al., 1977). We describe an infant treated by selective bronchial intubation. Intubation of the right main stem bronchus in order to collapse the left lung is a technically simple procedure and we feel that it should be used as the initial management for localized left PIE.

\section{Case report}

The baby was the first of twins born at 29 weeks gestation weighing $1.2 \mathrm{~kg}$. She required ventilatory support from birth with a fraction of inspired air that is oxygen $\left(\mathrm{F}_{1} \mathrm{O}_{2}\right)$ of 1.0 for severe respiratory distress syndrome which was confirmed radiologically. In the first $24 \mathrm{hr}$, the highest peak inspiratory pressure was $20 \mathrm{cmH}_{2} \mathrm{O}$ and the ventilatory rate never exceeded 30 breaths per min.

On day 2, hyperinflation of the right lung was noted but resolved spontaneously by day 5 and did

Reprint requests to Dr Smith. not recur. During this time her oxygen requirement also decreased, the $\mathrm{F}_{1} \mathrm{O}_{2}$ falling to $0 \cdot 3$. A left-sideof pneumothorax on day 5 was satisfactorily treated? using a chest drain connected to an underwater seab drain. A second left basal pneumothorax on day $\varepsilon^{6}$ required a further intercostal drain.

Pulmonary interstitial emphysema of the left lungs was first documented on day 12 with contralateratmediastinal shift, but this initially did not result in any clinical deterioration and the $\mathrm{F}_{1} \mathrm{O}_{2}$ was unaltered at $0 \cdot 3$. However, on day 13 she developed a sever respiratory acidosis (arterial pH 7.15 $\left.\mathrm{PCO}_{2} 8.3 \mathrm{kPA}\right)$ requiring both an increase in the $\mathrm{F}_{1} \mathrm{O}_{2}$ and ventilatory rate with radiological evidence of increa $\neq$ ing left PIE, a large left emphysematous bulla whic mediastinal shift to the right, and right upper lobes collapse (Fig. 1).

The right main stem bronchus was selectivelyŏ intubated with dramatic clinical improvement. Only@ 90 min later, a repeat chest X-ray showed collapse of the left lung, a reduction in the size of the bulla and 3 re-expansion of the right upper lobe (Fig. 2). Selective bronchial intubation was continued for 48 hrọ. after which time it was replaced by a routine nasotracheal tube. Mild left PIE without bulla 3 . formation was noted 3 days later, but this was notio associated with any change in her clinical state.

Assisted ventilation was required for a further 19 days. A large patent ductus arteriosus was ligated on day 31 .

She was discharged at the age of $2 \frac{1}{2}$ months, $\rightarrow$ weighing $2.25 \mathrm{~kg}$ when a chest X-ray showed mild으․ bronchopulmonary dysplasia. She has continued tow do well.

\section{Discussion}

Macklin (1939) described the histopathologicalo development of PIE in experimental animals, indiso cating that the air leaks from overdistended alveolic into the pulmonary perivascular sheaths and that air. ${ }^{\text {? }}$ may than track to the mediastinum. This results in an 


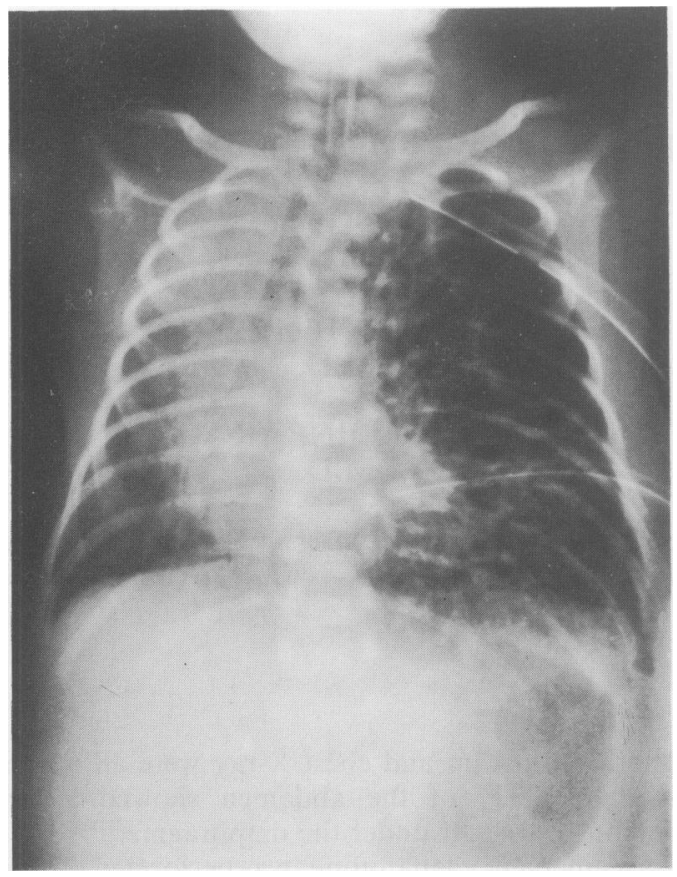

FIG. 1. Left emphysematous bulla with mediastinal shift and collapse of right upper lobe.

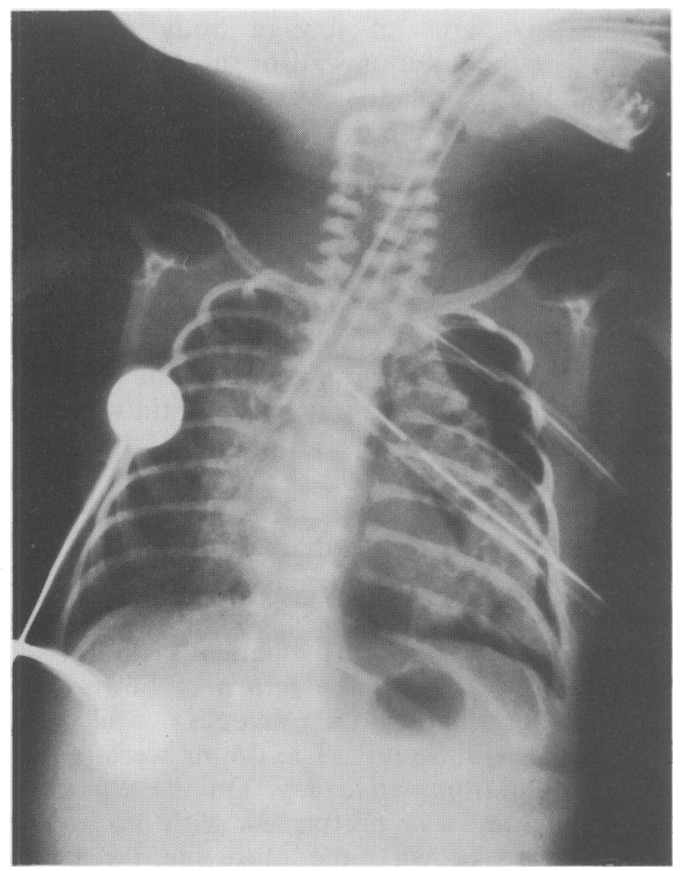

FIG. 2. Collapse of left bulla and re-expansion of right upper lobe. increase in perivascular sheath pressure with diminished blood flow to the affected part of the lung with serious clinical consequences. Extension of the perivascular air may then cause a pneumothorax, pneumomediastinum or pneumopericardium. If PIE can be treated these serious complications may be prevented.

Selective bronchial intubation of the right main stem bronchus had a dramatically beneficial clinical and radiological effect in this infant. It is a technically simple procedure (Brooks et al., 1977). The endotracheal tube was cut $2 \mathrm{~cm}$ longer than usual, the infant's head turned to the left and the tube inserted in the standard manner. The shape of the bifurcation of the trachea permits easy access to the right main bronchus.

We suggest that the collapse of the right upper lobe may have been due to kinking of the right upper lobe bronchus by the mediastinal shift and when this was reduced, the bronchus re-opened and the upper lobe re-expanded. The subsequent recurrence of mild left PIE can be explained by the removal of the endobronchial tube after only $48 \mathrm{hr}$. Other authors (Brooks et al., 1977) suggest that selective intubation should be continued for at least 5 days to prevent recurrence. This case confirms that localized PIE can be treated easily by selective bronchial intubation with dramatic clinical improvement.

\section{Acknowledgments}

We would like to thank Dr P. J. Congdon, Consultant Paediatrician, for permission to report this case.

\section{References}

Bamer, C.R., Brennan, M.J., Doyle, C. \& Poole, C.A. (1980) Surgical resection for pulmonary interstitial emphysema in the newborn infant. Journal of Pediatrics, 93, 656.

Brooks, J.G., Bustamente, S.A., Koops, B.L., Hilton, S., CooPER, D., Wesenberg, R.L. \& Simmons, M.A. (1977) Selective bronchial intubation for the treatment of severe localised pulmonary interstitial emphysema in newborn infants. Journal of Pediatrics, 91, 648.

Coradello, H., Fodor, M. \& Simbruner, G. (1980) Interstitelles emphyseum bei. Beatmeter neugeborenen. Klinische Padiatrie (Stuttgart), 192/5, 404.

MACKLIN, C.C. (1939) Transport of air along sheaths of pulmonic blood vessels from alveoli to mediastinum. Archives of Internal Medicine, 64, 913.

NG, K.P.K. \& EASA, D. (1979) Management of interstitial emphysema by high frequency low positive pressure hand ventilation in the neonate. Journal of Pediatrics, 95, 117. 